\title{
Nuclear Medicine Technologists' Perception and Current Assessment of Quality: A Society of Nuclear Medicine and Molecular Imaging Technologist Section Survey
}

\author{
April Mann, CNMT, NCT, RT(N), FSNMMI-TS ${ }^{1}$, Mary Beth Farrell, CNMT, FSNMMI-TS², Jessica Williams, CNMT, \\ RT(N), FSNNMI-TS ${ }^{3}$, and Danny Basso, CNMT, NCT FSNMMI-TS ${ }^{4}$ \\ ${ }^{1}$ Hartford HealthCare Corporation, Hartford, Connecticut; ${ }^{2}$ Intersocietal Accreditation Commission, Ellicott City, Maryland; \\ ${ }^{3}$ Hospital of the University of Pennsylvania, Philadelphia, Pennsylvania; and ${ }^{4}$ University Health Care System, Augusta, Georgia
}

\begin{abstract}
CE credit: For CE credit, you can access the test for this article, as well as additional JNMT CE tests, online at https://www.snmmilearningcenter.org. Complete the test online no later than June 2020. Your online test will be scored immediately. You may make 3 attempts to pass the test and must answer $80 \%$ of the questions correctly to receive $1.0 \mathrm{CEH}$ (Continuing Education Hour) credit. SNMMI members will have their CEH credit added to their VOICE transcript automatically; nonmembers will be able to print out a CE certificate upon successfully completing the test. The online test is free to SNMMI members; nonmembers must pay $\$ 15.00$ by credit card when logging onto the website to take the test.
\end{abstract}

In 2015, the Society of Nuclear Medicine and Molecular Imaging Technologist Section (SNMMI-TS) launched a multiyear quality initiative to help prepare the technologist workforce for an evidence-based health-care delivery system that focuses on quality. To best implement the quality strategy, the SNMMI-TS first surveyed technologists to ascertain their perception of quality and current measurement of quality indicators. Methods: An internet survey was sent to 27,989 e-mail contacts. Questions related to demographic data, perceptions of quality, quality measurement, and opinions on the minimum level of education are discussed in this article. Results: A total of $4,007(14.3 \%)$ responses were received. When asked to list 3 words or phrases that represent quality, there were a plethora of different responses. The top 3 responses were image quality, quality control, and technologist education or competency. Surveying patient satisfaction was the most common quality measure $(80.9 \%)$, followed by evaluation of image quality $(78.2 \%)$. Evaluation of image quality $(90.3 \%)$ and equipment functionality $(89.4 \%)$ were considered the most effective measures. Technologists' differentiation between quality, quality improvement, quality control, quality assurance, and quality assessment seemed ambiguous. Respondents were confident in their ability to assess and improve quality at their workplace (91.9\%) and agreed their colleagues were committed to delivering quality work. Of note, $70.7 \%$ of respondents believed that quality is directly related to the technologist's level of education. Correspondingly, respondents felt there should be a minimum level of education $(99.5 \%)$ and that certification or registry should be required $(74.4 \%)$. Most respondents $(59.6 \%)$ felt that a Bachelor's degree should be the minimum level of education, followed by an Associate's degree (40.4\%). Conclusion: To best help nuclear medicine technologists provide quality care, the

Received Apr. 13, 2017; revision accepted Apr. 13, 2017.

For correspondence or reprints contact: April Mann, System Quality Manager, Heart \& Vascular Institute, Hartford Healthcare Corporation, 80 Seymour St., Hartford, CT 06102.

E-mail: april.mann@hhchealth.org

Published online May 4, 2017

COPYRIGHT (C) 2017 by the Society of Nuclear Medicine and Molecular Imaging.
SNMMI-TS queried technologists to discern perceptions of quality in nuclear medicine. The results show that technologists believe image quality and quality control are the most important determinants. Most respondents felt that quality is directly related to the level of education of the technologist acquiring the scan. However, the responses obtained also demonstrated variation in perception of what represents quality. The SNMMI-TS can use the results of the study as a benchmark of current technologists' knowledge and performance of quality measures and target educational programs to improve the quality of nuclear medicine and molecular imaging.

Key Words: quality; image quality; technologist; quality improvement

J Nucl Med Technol 2017; 45:67-74

DOI: 10.2967/jnmt.117.194704

$\mathbf{I}$ 2001, the Institute of Medicine (IOM) published Crossing the Quality Chasm: A New Health System for the 21st Century (1). This landmark report proclaimed that gaps exist in health care across the United States, evidenced by a lack of consistent, high-quality health care for all people. In addition, the report claimed that the U.S. health-care system inadequately translates medical knowledge and evidence-based research into practice. Further, the system does not advance the use of new technology safely and appropriately.

As a result of the IOM's publication, health care in the 21 st century is undergoing a dramatic change, morphing from a system of quantity to a system of quality by targeting evidence-based outcomes and patient satisfaction (2). Subsequently, insurance payers, including the Centers for Medicare and Medicaid Services, now link payment to value rather than volume. It is believed that focusing on value through the use of a value-based payment system will help control rising health-care costs (3). 
These forces, coupled with external pressures such as job shortages, declining reimbursement, radiation exposure scrutiny, and imaging overutilization, are molding the future of nuclear medicine and molecular imaging (4-7).

\section{QUALITY DEFINITION}

Quality may be defined differently among individuals. Although it may mean different things to different people, it is important to have a standard baseline definition to build on. Manufacturing defines quality as "measures of excellence or a state of being free from defects, deficiencies, and significant variation" (8). How does this definition of quality apply to health care? The IOM defines quality in health care as services for individuals and populations that increase the likelihood of desirable outcomes that are consistent with current medical knowledge (9). Patient care must be based on scientific, medical evidence that improves the health and life of the patient while also taking into account the patient's preferences (10). Specifically, quality care is patient-centered, relying on evidence-based outcomes and appropriateness. The Agency for Health Care Research \& Quality defines health care quality "as doing the right thing, for the right patient, at the right time, in the right way to achieve the best possible results" (11). In diagnostic imaging, "with the right dose" has been added to this definition.

\section{SOCIETY OF NUCLEAR MEDICINE AND MOLECULAR IMAGING TECHNOLOGIST SECTION (SNMMI-TS) AND QUALITY}

At the 2015 annual meeting, the SNMMI-TS launched a multiyear quality initiative to help prepare the technologist workforce for an evidence-based health-care delivery system that focuses on quality (12). The goals of the initiative are to raise awareness, ensure appropriate training and competence of technologists, emphasize safety, and collaborate with stakeholders in the nuclear medicine community. To best implement this quality strategy, the SNMMI-TS first needed to understand technologists' knowledge and perceptions of quality health care.

To aid in discovering how quality is currently viewed and measured, the SNMMI-TS retained an outside consultant to conduct a critical research survey. The objective of the survey was to ascertain nuclear medicine technologists' perception of quality and current measurement of quality indicators. The results of the study will be used to establish baseline quality metrics and to guide the development of a quality program tailored to the needs of nuclear medicine and molecular imaging technologists.

\section{MATERIALS AND METHODS}

The SNMMI-TS engaged McKinley Advisors (McKinley), a consulting firm with expert knowledge of professional associations and survey methodology, to conduct an internet survey of nuclear medicine technologists. The process involved 5 stages: project planning and immersion, meeting with focus groups and the Quality Committee, an electronic survey, data analysis, and summation of the findings and opportunities. First, the consultants queried a focus group of 10 technologists from various settings and diversified experience to establish a baseline to build the survey. Contact lists from the SNMMI-TS, Nuclear Medicine Technology Certification Board, and the American Registry of Radiologic Technologists were used to sample technologists. E-mail invitations were sent in July 2016 with multiple follow-up reminders. A total of 27,989 e-mails were delivered. During a meeting in September 2016, the results of the survey were reviewed and discussed by members of the Quality Committee, Board of Directors, and SNMMI staff.

The survey design included 35 questions organized into 6 categories: demographic (17), the perception of quality (2), quality measures (6), education and professional development (5), professional societies (2), and trends and challenges (3) (Supplemental Table 1 [supplemental materials are available at http://tech.snmjournals. org]). A combination of multiple-choice, dichotomous, rating, and open-ended questions were used. Respondents were allowed to skip questions. For the purpose of this article only, the demographic data, perceptions of quality, quality measurement, and opinions on the minimum level of education will be discussed. The remaining question categories will be considered in a separate publication.

\section{Data Management and Statistical Analysis}

When the survey results were analyzed, comparisons were made between key segments of the population based on professional position, education level, tenure in the field, and area of expertise. Respondent positions were grouped into 4 categories: staff technologist, chief or senior technologist, administrator, and other. The level of education was grouped into no degree (certificate), Associate's degree, Bachelor's degree, and Master's degree or postgraduate education. The level of education was further consolidated into Associate's degree or less and Bachelor's degree and higher for comparisons. Expertise was grouped into cardiology, molecular imaging or oncology, general nuclear medicine, radiology, and other.

For ranking questions, responses of 4 and 5 were combined into an "effective" group, and responses of 1 and 2 were combined into a "not effective" group. Similarly, Likert scale questions were combined into groups of "agree" (strongly agree and somewhat agree), "neither agree nor disagree," and "disagree" (strongly disagree and somewhat disagree). Open-ended responses were grouped on the basis of similar responses, and word cloud associations were created.

The data were cleaned and examined for outliers, normality, and correlations and analyzed using SPSS (version 22; SPSS). The categoric data were expressed as the number and percentage of respondents per question. $\chi^{2}$ tests were used to determine differences between the key population segments. Multinomial logistic regression analysis was used to detect differences between the quality metrics and the key population segments. Logistic regression analysis was used identify sections of the population that favor an Associate's degree versus a Bachelor's degree as the minimum level of education.

\section{RESULTS}

\section{Demographic Data}

Of the 27,989 e-mails delivered, there were 4,007 responses $(14.3 \%)$, of which there were 2,698 complete responses and 1,309 partial responses. The respondents represented a mix of current (41.2\%) and former SNMMITS members $(37.6 \%)$ together with $18.9 \%$ who had never been a member of the Society (Table 1). Staff technologists 
TABLE 1

Respondent Demographic Data

\begin{tabular}{|c|c|c|c|}
\hline Variable & $n(\%)$ & Variable & $n(\%)$ \\
\hline Membership status & 3,811 & Work setting & 2,481 \\
\hline SNMMI-TS member & $1,609(41.2)$ & Hospital (academic/community) & $1,501(60.5)$ \\
\hline Former member & $1,466(37.6)$ & Nonhospital (private/outpatient) & $722(29.1)$ \\
\hline Never a member & 736 (18.9) & Other & $258(10.4)$ \\
\hline Current position & 3,906 & Area of expertise & 2,614 \\
\hline Staff technologist & $1,743(44.6)$ & Nuclear medicine & $1,663(63.6)$ \\
\hline Chief/lead technologist & $1,237(31.7)$ & Cardiology & $532(20.4)$ \\
\hline Manager/administrator & $213(5.4 \%)$ & Molecular imaging +oncology & $283(10.8)$ \\
\hline Educator/instructor & $104(2.7)$ & Radiology & $68(2.6)$ \\
\hline Student & $64(1.6)$ & Medical physics & $23(0.9)$ \\
\hline Researcher & $33(0.8)$ & Radiopharmacy & $14(0.5)$ \\
\hline Unemployed & $157(4.0)$ & Other & $31(1.2)$ \\
\hline Retired & $81(2.1)$ & Years working in field & 2,601 \\
\hline Other & $274(7.0)$ & $<1$ & $120(4.6)$ \\
\hline$\%$ time working in nuclear medicine & 2,499 & $2-5$ & $336(12.9)$ \\
\hline$<50 \%$ & 405 (16.2) & $6-10$ & $447(17.2)$ \\
\hline $50 \%-80 \%$ & $401(16.0)$ & $11-20$ & $686(26.4)$ \\
\hline$>80 \%$ & $1,693(67.7)$ & $>20$ & $1,012(38.9)$ \\
\hline Certifications & & Education & 2,660 \\
\hline NMTCB (CNMT) & $2,543(63.4)$ & Certificate & $118(4.4)$ \\
\hline ARRT (RT(N)) & $1,467(36.6)$ & Associate's degree & $758(28.5)$ \\
\hline Specialty & & Bachelor's degree & $1,437(54.0)$ \\
\hline $\mathrm{CT}$ & $394(9.8)$ & Master's degree or higher & 347 (13.0) \\
\hline PET & $032(6.0)$ & Currently licensed & 1,977 \\
\hline NCT & $133(3.3)$ & Yes & $1,882(95.2 \%)$ \\
\hline MRI & $73(1.8)$ & No & $95(4.8)$ \\
\hline None & $38(1.4)$ & Sex & 618 \\
\hline State licensure required & 2,746 & Female & $1,590(60.7)$ \\
\hline Yes & $1,997(72.7)$ & Male & $1,028(39.3)$ \\
\hline No & $656(23.9)$ & & \\
\hline Unsure/outside of United States & $93(3.4)$ & & \\
\hline Age $(y)$ & 2651 & & \\
\hline$<25$ & $67(2.5)$ & & \\
\hline $25-34$ & $574(21.7)$ & & \\
\hline $35-44$ & 709 (26.7) & & \\
\hline $45-54$ & 616 (23.2) & & \\
\hline $55-64$ & $562(21.2)$ & & \\
\hline$>65$ & $123(4.6)$ & & \\
\hline
\end{tabular}

NMTCB = Nuclear Medicine Technology Certification Board; CNMT = Certified Nuclear Medicine Technologist; ARRT = American Registry of Radiologic Technologists; NCT = Nuclear Cardiology Technologist.

comprised $44.6 \%$ of respondents, with an additional $31.7 \%$ working as chief or senior technologist. General nuclear medicine was the main area of expertise $(63.6 \%)$, followed by cardiology $(20.4 \%)$ and molecular imaging (10.8\%). Most respondents worked in a hospital setting $(60.5 \%)$, and most $(67.7 \%)$ spent more than $80 \%$ of their time working in nuclear medicine.

Respondents represented varying levels of experience within the field. Thirty-nine percent had more than $20 \mathrm{y}$ of experience, whereas $17.5 \%$ had 5 y or fewer. The Nuclear Medicine Technology Certification Board (63.4\%) certified most, trailed by the American Registry of Radiologic Technologists (36.6\%). CT was the most common specialty certification $(9.8 \%)$, followed by PET $(4.2 \%)$ and nuclear cardiology (nuclear cardiology technologist) (3.3\%). More than half $(54.0 \%)$ of the respondents indicated that their highest level of education was a Bachelor's degree, $28.5 \%$ reported an Associate's degree, and 13.0\% a Master's degree or higher. Respondents with only certificates comprised $4.4 \%$ of those surveyed. State licensure was required for $75.3 \%$ of those surveyed, and $95.2 \%$ of those respondents indicated that they were licensed.

\section{Perception of Quality}

Respondents were asked to state 3 words or phrases that came to mind when thinking about quality in nuclear medicine. There was a myriad of variations, with almost 2,900 unique responses. Therefore, to consolidate these into key concepts, we grouped the responses into similar themes and assayed the results in a word cloud (Fig. 1). Image quality, quality control (QC) or equipment functionality, and technologist education or competence were the top 3 concepts. Respondents were also asked to explain what quality in the workplace meant to them. Again, the variation in 


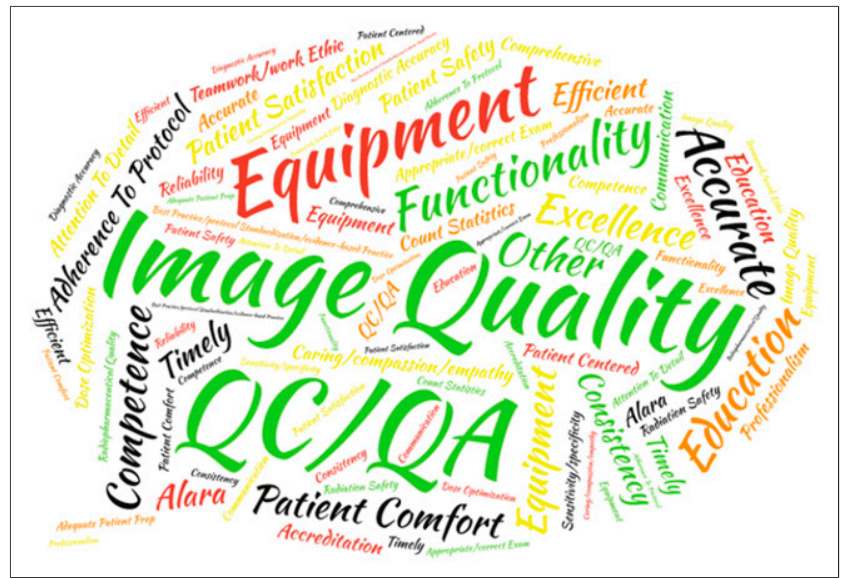

FIGURE 1. Technologists' survey responses when asked what 3 words or phrases come to mind when thinking of quality in nuclear medicine and molecular imaging. The larger the text font, the more frequently word was used.

responses was considerable, so the responses were collapsed on the basis of theme. The clustered responses demonstrated that $30.1 \%$ of respondents felt quality in the workplace means providing the best patient experience possible. The impressions ranged from making sure patients received excellent care to ensuring that patients were satisfied. The next most popular theme was obtaining the most accurate image possible $(22.3 \%)$.

\section{Quality Measures}

Respondents were asked a series of questions about their facility's quality measurement (Fig. 2). First, respondents selected which aspects of quality were measured. Patient satisfaction was the most frequently selected measure by $80.9 \%$ of the interviewees. Evaluation of image quality was second at $79.1 \%$, followed by the regularity of equipment checks at $78.2 \%$.

Respondents then ranked the effectiveness of the measures performed at their facility. The measures considered most effective were evaluation of image quality (90.3\%) and functionality of equipment (89.4\%), followed by the adequacy of patient preparation and accuracy of image interpretation, both at $88.1 \%$. Although patient satisfaction was the most frequently performed quality assessment, it was not felt to be the most effective. Many respondents maintained there is no correlation between a positive patient experience and accuracy of the results. Nine other measures were ranked more effective in improving quality than assessing patient satisfaction.

Finally, respondents indicated that evaluation of image quality and detecting motion or artifacts was the most frequently performed measurement $(75.2 \%)$, being performed daily or monthly. Evaluation of equipment functionality was next at $72.4 \%$ along with adequacy of patient preparation also at $72.4 \%$. Thus, the 3 most frequently performed measures were also considered the 3 most effective actions.

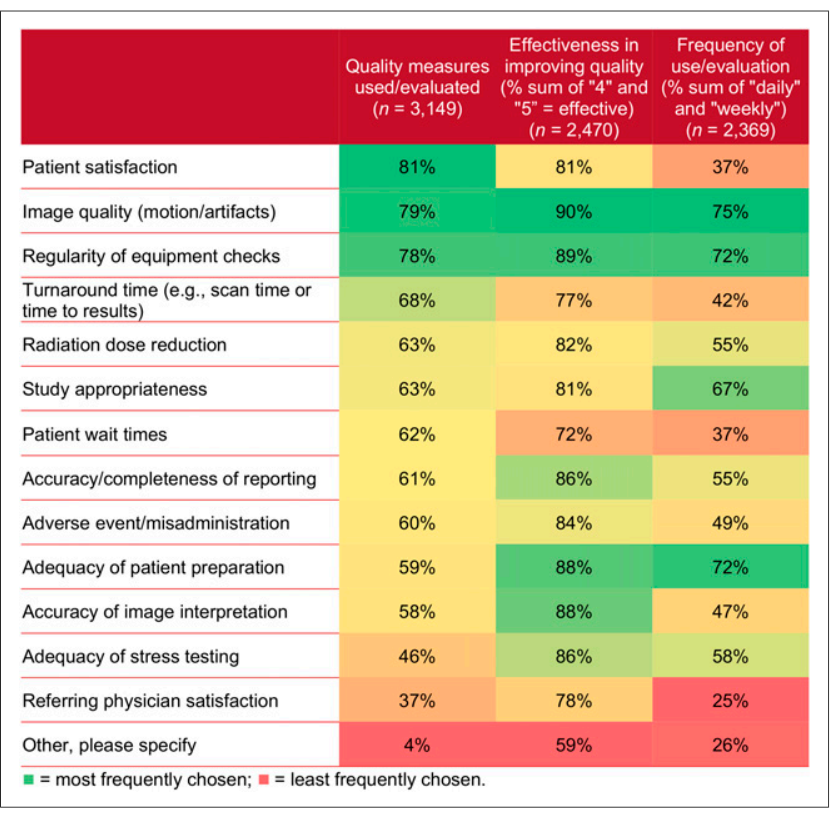

FIGURE 2. Quality measure performance, effectiveness, and frequency.

\section{Quality Statements}

Respondents were asked to rank their level of agreement with 7 statements related to quality (Fig. 3). Respondents were confident in their ability to assess and improve quality at their workplace (91.9\%), with the least experienced technologists the most confident $(P=0.01)$. Most respondents also agreed that their colleagues are committed to consistently delivering quality work (84.8\%). Respondents were less sure that they are kept informed of organizational quality initiatives $(70.2 \%)$. There was a difference in agreement based on position in that $90.8 \%$ of administrators felt they were notified about initiated quality measures, but only $82.4 \%$ of staff and $83.3 \%$ of chief technologists felt informed $(P=0.04)$.

Of note, $70.7 \%$ of respondents believed that quality is directly related to the level of education of the technologist obtaining the scan. Not surprisingly, there was a significant difference in agreement between those with and without a Bachelor's degree or higher. Of those with a Bachelor's degree or higher, $84.5 \%$ agreed that quality is related to

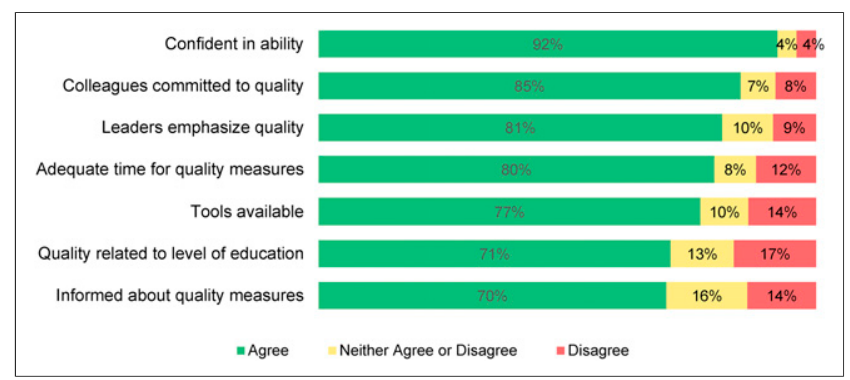

FIGURE 3. Respondent level of agreement with 7 quality statements. 
the level of education compared with those without a Bachelor's degree $(74.5 \%)(P<0.0001)$.

Finally, $80.3 \%$ of respondents felt they were given adequate time to perform quality work. However, more experienced technologists were less likely to feel that they receive sufficient time to perform quality work compared with less experienced technologists $(P=0.04)$.

\section{Minimum Education Level}

Following up on the question of whether quality is related to the level of education, respondents were asked to indicate their opinion on the minimum level of education that should be achieved by nuclear medicine and molecular imaging technologists (Fig. 4). Respondents agreed that there should be a minimum level of education, with only $0.5 \%$ stating there should be no minimum level required. A Bachelor's degree was selected by most (59.6\%) compared with an Associate's degree (40.4\%). Most respondents $(74.4 \%)$ also felt certification or registry should be required.

Several trends for the level of education were seen based on the key demographic variables. Administrators $(71.4 \%)$ were more likely than staff and chief technologists $(57.6 \%$ and $57.2 \%$, respectively) to believe a Bachelor's degree should be required $(P=0.02)$. Those working in a hospital $(60.9 \%)$ were more likely to feel a Bachelor's degree was necessary compared with respondents working in the nonhospital setting $(54.8 \%)(P=0.03)$.

Both time working in the field and age showed trends, with most respondents working in the field $5 \mathrm{y}$ or fewer believing a Bachelor's degree was important. After $5 \mathrm{y}$ in the field, the percentage begins to decline (maximum, $65.1 \%$; minimum, 54.9\%) $(P=0.02)$. For the age variable, with increasing age, the proportion of technologists who felt a Bachelor's degree should be required decreased from $71.1 \%$ at $18-24$ y old down to $48.3 \%$ for those older than $65 \mathrm{y}$.

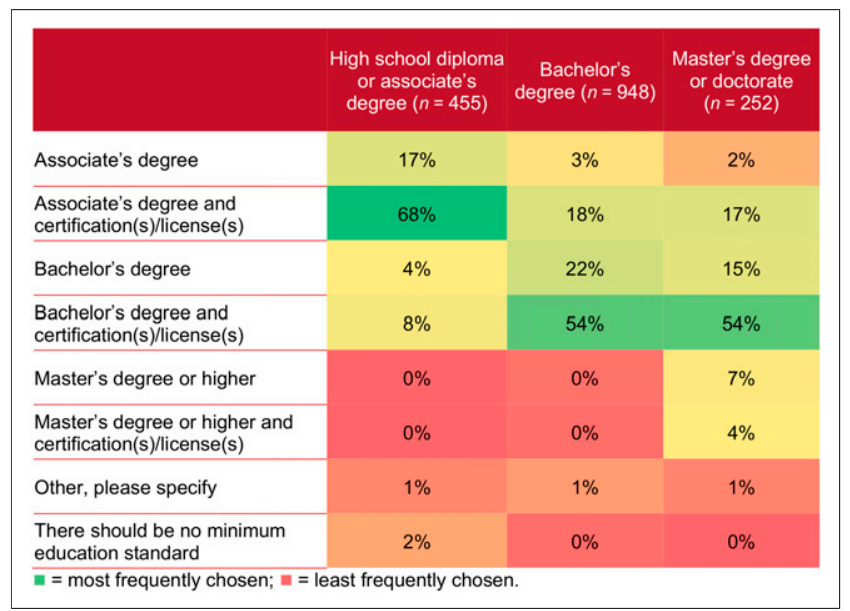

FIGURE 4. Minimum education standard for nuclear medicine technologists.

\section{DISCUSSION}

Quality versus quantity has become a call to arms in health care. To best help nuclear medicine technologists provide quality care, the SNMMI-TS queried technologists from multiple angles to discern beliefs related to quality in nuclear medicine. The results show technologists believe image quality and QC are the most important determinants. The surveyed technologists were confident in their ability to assess and improve quality in the workplace and that their colleagues are also committed to delivering quality work. Also, most respondents felt that quality is directly related to the level of education of the technologist acquiring the scan. However, the responses obtained also demonstrated variation in perception of what represents quality.

From the profusion of conflicting definitions of quality in nuclear medicine provided by respondents, it is apparent that there is substantial confusion among technologists. The differentiation between quality, quality improvement (QI), QC, quality assurance, and quality assessment seems ambiguous. Before any initiatives to advance quality can be formulated, the terms must be disassociated and stipulated (Table 2).

QI has been defined as a formal process of examining and then improving performance or enhancing patient care based on the analysis of data (13). The relevant concept here is an improvement based on the analysis of data. In nuclear medicine, QI programs should emphasize efficient and accurate patient care, patient safety, staff safety, and the patient's experience (14). When respondents were asked to describe quality in the workplace, the second most common response was providing the best patient experience possible.

Although QC and quality assurance are often used interchangeably, there is a difference. QC is defined as procedures to ensure that equipment or processes adhere to established standards. It is a form of monitoring that indicates the need for corrective action. If the monitored parameter falls outside of the laboratory's defined criteria, staff intervene. In nuclear medicine, a good example is the procedures performed daily on $\gamma$-cameras before imaging patients such as measuring uniformity (flood). A uniformity test evaluates the current camera performance against the results from performance testing. For instance, if the integral or differential uniformity results fall outside of the laboratory's threshold, the equipment is not used until the problem is corrected.

Quality assurance focuses on assurance; the act of making certain or giving confidence (15). In medicine, it is processes or programs intended to improve or assure the quality of patient care through evaluation or assessment of the quality of patient care, that is, quality assessment - the evaluation of the quality of care. Quality assurance identifies problems and designs activities to correct the issue and then follow up with monitoring to ensure the effectiveness of the correction (16). The goal is to prevent problems from occurring, detect if problems occur, and correct the problems to improve care (17). 


\begin{tabular}{ll}
\hline \multicolumn{1}{c}{ Term } & $\begin{array}{c}\text { Care based on scientific, medical evidence that improves the health and life of the patient while also } \\
\text { considering the patient's preferences. }\end{array}$ \\
\hline Quality care & $\begin{array}{c}\text { The formal process of examining and then improving the performance or enhancing patient care } \\
\text { based on the analysis of data. }\end{array}$ \\
QI & $\begin{array}{l}\text { Procedures to ensure that equipment or processes adhere to established standards. } \\
\text { QC }\end{array}$ \\
$\begin{array}{l}\text { The evaluation of the quality of care. } \\
\text { Quality assurance }\end{array}$ & $\begin{array}{l}\text { The processes or programs intended to improve or assure the quality of patient care } \\
\text { through evaluation or assessment. }\end{array}$ \\
\hline
\end{tabular}

Quality health care, as previously defined, is patientcentered care built on a framework of evidence-based outcomes and appropriateness (18). Quality is demonstrated in the ability to accomplish 6 aims that were promulgated in the IOM's Crossing the Quality Chasm: A New Health System for the 21st Century (1). Health care must be safe, efficient, effective, personalized, timely, and equitable (Table 3).

To improve the quality, access, and affordability of health care, Congress passed the Patient Protection and Affordable Care Act of 2010, also known as the Affordable Care Act or Obamacare (19). A little-discussed provision in the Act, Title 3, calls for substantial efforts and investment to improve the quality of health care. To accomplish this, the Act mandated the establishment of an annual national quality strategy. The 2016 National Quality Strategy marked the fifth anniversary of the document (20). The 2016 edition continues to promote 6 quality priorities (Table 4). Several of these priorities can be used in nuclear medicine to improve the quality of care.

The first of the 6 priority strategies is to make care safer by reducing harm occurring from the delivery of care and reducing harm from inappropriate or unnecessary care (21). Unique to nuclear medicine, optimization of radiation dose to obtain the best image quality at the lowest possible radiation dose should take precedence (22). Also, technologists can help to make sure that studies are performed for the appropriate reason by following published appropriate use criteria from the SNMMI, American Society of Nuclear Medicine, and the American College of Radiology (23-25).
The second priority directly applicable to nuclear medicine is already a focus for technologists based on the results of this survey, albeit it was viewed as less effective. This strategy states health care should be patient- and family centered and engage patients in their care. Assessment of patient satisfaction was the most commonly performed quality measure. Nuclear medicine technologists can continue to comply with this priority by concentrating on patient-centric care by adapting doses and procedures individually for each patient and not using a "one size fits all" approach.

The third priority promotes effective communication and coordination of care across care settings. Quality activities that quantify and promote the precision and timeliness of reporting are fundamentally essential. Referring physicians base patient care and management decisions on the results of nuclear medicine examinations. Therefore, reports must be timely and communicate the results accurately and consistently (26-28).

\section{Next Steps}

The SNMMI-TS is committed to preparing technologists for the challenges of transitioning from an era of quantity into the new demanding era of quality in health care. The survey results identified an apparent knowledge gap in technologists' level of understanding related to quality, its measurement, and methods to achieve. As a first step, the SNMMI-TS needs to establish a standard lexicon for quality, QI, QC, quality assurance, and quality assessment.

TABLE 3

Six Aims for Quality Health Care

\begin{tabular}{|c|c|}
\hline Aim & Definition \\
\hline Safe & Avoidance of injuries or harm from care that is intended to help patients \\
\hline Efficient & Avoidance of waste, which includes wasting equipment, supplies, ideas, time, and energy \\
\hline Effective & $\begin{array}{l}\text { Provision of care based on scientific knowledge and evidence along with the avoidance of care } \\
\text { that is not likely to benefit the patient }\end{array}$ \\
\hline $\begin{array}{l}\text { Personalized or } \\
\text { patient-centered }\end{array}$ & Provision of care that respects the patient's values and responds to the patient's preferences and needs \\
\hline Timely & Reduction of time waiting and potentially harmful delays in care for those who give and receive care \\
\hline Equitable & $\begin{array}{l}\text { Provision of care where quality does not vary based on characteristics such as sex, ethnicity, geographic } \\
\text { location, or socioeconomic status }\end{array}$ \\
\hline
\end{tabular}




\begin{tabular}{|ll}
\hline \multicolumn{1}{c}{ Priority } & \multicolumn{1}{c}{ Long-term goal } \\
\hline Make care safe by reducing harm from care & $\begin{array}{l}\text { Decrease hospital admissions and readmissions } \\
\text { Reduce medical errors and harm from medical care }\end{array}$ \\
\hline $\begin{array}{l}\text { Ensure patients and families are engaged in } \\
\text { care decisions }\end{array}$ & $\begin{array}{l}\text { Reduce inappropriate or unnecessary care } \\
\text { Improve patient experience }\end{array}$ \\
\hline $\begin{array}{l}\text { Make communication and coordination } \\
\text { of care effective }\end{array}$ & $\begin{array}{l}\text { Use shared decision making between providers and patients } \\
\text { Improve communication and transitions across settings }\end{array}$ \\
$\begin{array}{ll}\text { Promote prevention of leading causes } \\
\text { of death }\end{array}$ & $\begin{array}{l}\text { Improve quality of life for chronically ill and disabled } \\
\text { Integrate care across communities and reduce health disparity }\end{array}$ \\
\hline $\begin{array}{l}\text { Work with communities to promote use } \\
\text { of best practices }\end{array}$ & $\begin{array}{l}\text { Promote healthy lifestyle } \\
\text { Make health care more affordable }\end{array}$ \\
\hline
\end{tabular}

Next, the SNMMI-TS needs to launch an awareness campaign to reinforce the technologist's vital role in assuring quality. Advocacy, leadership, public relations, outreach, and collaboration are all important components. At the 2015 annual meeting, the SNMMI-TS inaugurated its quality initiative with a "Committed to Quality" pledge. Further dissemination of that quality vision is needed.

The survey identified an immediate need for the development of education and training for technologists in the areas of quality. The Quality Committee is currently in the process of developing a program to be offered at chapter meetings and other venues to provide a complete overview of the aspects of quality and what technologists should know. The program will clarify what quality means. It will demonstrate how to measure quality and incorporate the 6 aims into practice. The program will illustrate how to provide patient-centered care and identify the human factors in providing safe quality patient care. The program will include considerations for clinical specialties such as cardiology, PET, oncology, and neurology.

Along with targeted educational offerings, the Society must develop tools to facilitate consistent, accurate care. The application of evidence-based care and outcomes drives high-level performance. Therefore, wider circulation and employment of published procedure standards and appropriate use criteria are needed. Toolkits for recommended quality measures and a framework for quality audits should be developed.

By focusing on quality, patients receive care that is more safe, accurate, reliable, respectful, available, and integrated. Technologists benefit by increased job and personal satisfaction from improving health, meeting patient's needs, and enhancing the quality of life for those who receive their care.
A major limitation of this study was the modest response rate of $14.3 \%$, overall, and $9.6 \%$ for complete responses. However, this response rate is similar to previously reported rates in the literature for electronic surveys (29). The survey may also be limited by an inherent bias in the type of person who is likely to respond to a survey. However, individuals with positive or negative perceptions may be equally likely to respond.

\section{CONCLUSION}

The results of the SNMMI-TS quality survey demonstrate that most technologists perceive quality to be related to image quality and QC. Nuclear medicine technologists are confident in their ability to assess and improve quality and believe their colleagues are committed to quality. In addition, technologists believe there should be a minimum level of education along with certification or registry. However, the survey identified an apparent knowledge gap in the degree of understanding related to the definition of quality, its measurement, and methods to achieve. The SNMMI-TS can use the results of the study as a benchmark of current technologists' knowledge and performance of quality measures and target educational programs to improve the quality of nuclear medicine and molecular imaging.

\section{DISCLOSURE}

Danny Basso, April Mann, and Jessica Williams are members of the Society of Nuclear Medicine and Molecular Imaging Technologist Section Leadership. Danny Basso and April Mann are speakers and consultants for Astellas Pharma US, Inc. No other potential conflict of interest relevant to this article was reported. 


\section{ACKNOWLEDGMENTS}

We gratefully thank Nikki Wenzel-Lamb, Director of Leadership and SNMMI-TS Administrator, and Sukhjeet Ahuja, MD MPH, Director of Evidence and Quality, for their assistance in conducting this survey and support of SNMMI-TS quality efforts.

\section{REFERENCES}

1. Institute of Medicine (US) Committee on Quality of Health Care in America. Crossing the Quality Chasm: A New Health System for the 21st Century. Washington, DC: National Academy Press; 2001.

2. Bendix J. From quantity to quality: meeting the new demands of value-based care Making quality metrics work for your practice. Medical Economics website. http:// medicaleconomics.modernmedicine.com/medical-economics/news/quantity-qualitymeeting-new-demands-value-based-care?page $=$ full. February 26, 2105. Accessed April 18, 2017.

3. Better S. Healthier: an historic announcement, HHS sets clear goals and timeline for shifting Medicare reimbursements from volume to value. HHS.gov website. https://wayback.archive-it.org/3926/20170127185400/https://www.hhs.gov/about/ news/2015/01/26/better-smarter-healthier-in-historic-announcement-hhs-sets-cleargoals-and-timeline-for-shifting-medicare-reimbursements-from-volume-to-value.html. January 26, 2015. Accessed April 18, 2017.

4. Occupational Outlook Handbook: nuclear medicine technologists. The United States Department of Labor Bureau of Labor Statistics website. https://www.bls. gov/ooh/healthcare/nuclear-medicine-technologists.htm. Accessed April 18, 2017.

5. Schelbert HR. Nuclear medicine at a crossroads. J Nucl Med. 2011;52(suppl 2):10S-15S.

6. Fazel R, Krumholz H, Yongfei S, et al. Exposure to low-dose ionizing radiation from medical imaging procedures. N Engl J Med. 2009;361:849-857.

7. Brenner DJ, Hricak H. Radiation exposure from medical imaging: time to regulate? JAMA. 2010;304:208-209.

8. How do you define quality? The Lean Journey website. http://www.aleanjourney. com/2012/02/how-do-you-define-quality.html. February 14, 2012. Accessed April 18, 2017.

9. Crossing the quality chasm: the IOM health care quality initiative. The National Academies of Sciences Engineering Medicine website. http://www.nationalacademies.org/ hmd/Global/News\%20Announcements/Crossing-the-Quality-Chasm-The-IOM-HealthCare-Quality-Initiative.aspx. Accessed April 18, 2017.

10. NCQA (National Committee for Quality Assurance). The Essential Guide to Health Care Quality. Washington, DC: National Committee for Quality Assurance; 2012. https://www.ncqa.org/Portals/0/Publications/Resource\%20Library/ NCQA_Primer_web.pdf.

11. A Quick Look at Quality. AHRQ Agency for Healthcare Research and Quality Archive website. https://archive.ahrq.gov/consumer/qnt/qntqlook.htm. Accessed April 18, 2017.

12. Mann A. SNMMI-TS Makes a Pledge Toward Quality. J Nucl Med Technol. 2014;42:8A
13. What is quality improvement? Duke Patient Safety-Quality Improvement website. http://patientsafetyed.duhs.duke.edu/module_a/introduction/introduction.html. Accessed April 18, 2017.

14. Farrell MB, Abreu SH. A practical guide to quality improvement in nuclear medicine. J Nucl Med Technol. 2012;40:211-219.

15. Quality Assurance vs Quality Control-Learning Resources. ASQ website. http:// asq.org/learn-about-quality/quality-assurance-quality-control/overview/overview.html. Accessed April 18, 2017.

16. Quality assurance, health care. MeSH-NCBI website. https://www.ncbi.nlm.nih. gov/mesh/68011785/. Accessed April 18, 2017.

17. Methods of quality assessment and assurance. In: Lohr KN, ed. Medicare: A Strategy for Quality Assurance: Volume 1. Washington, DC: Institute of Medicine National Academy Press; 1990:265-302.

18. Quality of health care. MeSH-NCBI website. https://www.ncbi.nlm.nih.gov/ mesh/68011787/. Accessed April 18, 2017.

19. HR 3590-111th Congress: Patient Protection and Affordable Care Act. GovTrack website. https://www.govtrack.us/congress/bills/111/hr3590. Accessed April 18, 2017.

20. The national quality strategy: fact sheet. AHRQ Agency for Healthcare Research and Quality website. https://www.ahrq.gov/workingforquality/about/nqs-factsheets/fact-sheet.html. Accessed April 18, 2017.

21. Radiology risks \& benefits for patients. Image Wisely website. http://www. imagewisely.org/Patients.aspx?CSRT $=15064518582923032199$. Accessed April $18,2017$.

22. Mammen L, White RD, Woodard PK, et al. ACR appropriateness criteria(R) on chest pain, suggestive of acute coronary syndrome. J Am Coll Radiol. 2011;8: $12-18$.

23. Johnson KA, Minoshima S, Bohnen NI, et al. Appropriate use criteria for amyloid PET: a report of the Amyloid Imaging Task Force, the Society of Nuclear Medicine and Molecular Imaging, and the Alzheimer's Association. Alzheimers Dement. 2013;9:e-1-e-16.

24. Hendel RC, Berman DS, Di Carli MF, et al. ACCF/ASNC/ACR/AHA/ASE/ SCCT/SCMR/SNM 2009 appropriate use criteria for cardiac radionuclide imaging: a report of the American College of Cardiology Foundation Appropriate Use Criteria Task Force, the American Society of Nuclear Cardiology, the American College of Radiology, the American Heart Association, the American Society of Echocardiography, the Society of Cardiovascular Computed Tomography, the Society for Cardiovascular Magnetic Resonance, and the Society of Nuclear Medicine. J Am Coll Cardiol. 2009;53:2201-2229.

25. Cerqueira MD. The user-friendly nuclear cardiology report: what needs to be considered and what is included. J Nucl Cardiol. 1996;3:350-355.

26. Graham MM. The PET/CT report: the most important part of the study. J Nucl Med. 2010;51:5-6.

27. Reiner BI. Strategies for radiology reporting and communication: part 1 -challenges and heightened expectations. J Digit Imaging. 2013;26:610-613.

28. Sinclair M, O'Toole J, Malawaraarachchi M, Leder K. Comparison of response rates and cost-effectiveness for a community-based survey: postal, internet and telephone modes with generic or personalised recruitment approaches. BMC Med Res Methodol. 2012;12:132.

29. Quality strategy CMS. 2016. CMS.gov website. https://www.cms.gov/Medicare/ Quality-Initiatives-Patient-Assessment-Instruments/QualityInitiativesGenInfo/ Downloads/CMS-Quality-Strategy.pdf. Accessed April 18, 2017. 